\title{
Substance use prevention services in juvenile justice and behavioral health: results from a national survey
}

Rodney Funk ${ }^{1 *}$ (D) Hannah K. Knudsen ${ }^{2}$, Larkin S. McReynolds ${ }^{3}$, John P. Bartkowski ${ }^{4}$, Katherine S. Elkington ${ }^{5}$, Ellen H. Steele ${ }^{6}$, Jessica M. Sales ${ }^{7}$ and Christy K. Scott ${ }^{8}$

\begin{abstract}
Background: This study examined the national availability of substance use prevention (SUP) within juvenile justice $(\mathrm{JJ})$ and their primary behavioral health $(\mathrm{BH})$ providers, and the relationships between the availability of SUP and agency-level measures of organizational structure, staffing, and youth characteristics. A three-stage national probability sampling process was used to select participants for a national survey that included, among other facets of community supervision (CS) and BH practices, questions on agency characteristics, youth characteristics, whether the agency/provider directly provided SUP services, and whether the agency/provider directly provided substance use and/or mental health treatment. This paper focuses on SUP services along with agency/provider and youth characteristics related to providing SUP.
\end{abstract}

Results: The response rate for both CS agencies $(n=195)$ and BH providers $(n=271)$ was $96 \%$. Complex samples logistic regression initially examined univariate associations of each variable and identified candidates for a final multivariate model. Overall, only one-third of CS and BH providers reported offering SUP services, with BH providers being significantly more likely than CS agencies to provide SUP services. In addition, likelihood of SUP waS significantly lower among agencies where the substance use distribution of the caseload was below the median. Controlling for master's level staff and the substance use distribution, CS agencies were about $67 \%$ less likely to offer SUP when compared to BH providers.

Conclusions: Given the high rates of substance use among justice-involved youth and that substance use is an established risk for several negative behaviors, outcomes, and health conditions, these findings suggest that evidence-based prevention services should likely be expanded in justice settings, and perhaps included as part of CS programs, even when youth do not initially present with SU service needs.

Keywords: National survey, Substance use prevention, Juvenile justice, Community supervision, Juvenile probation, Community behavioral health providers

\footnotetext{
* Correspondence: rfunk@chestnut.org

${ }^{1}$ Chestnut Health Systems, 448 Wylie Drive, Normal, IL 61761, USA

Full list of author information is available at the end of the article
}

(c) The Author(s). 2020 Open Access This article is licensed under a Creative Commons Attribution 4.0 International License, which permits use, sharing, adaptation, distribution and reproduction in any medium or format, as long as you give appropriate credit to the original author(s) and the source, provide a link to the Creative Commons licence, and indicate if changes were made. The images or other third party material in this article are included in the article's Creative Commons licence, unless indicated otherwise in a credit line to the material. If material is not included in the article's Creative Commons licence and your intended use is not permitted by statutory regulation or exceeds the permitted use, you will need to obtain permission directly from the copyright holder. To view a copy of this licence, visit http://creativecommons.org/licenses/by/4.0/ The Creative Commons Public Domain Dedication waiver (http://creativecommons.org/publicdomain/zero/1.0/) applies to the data made available in this article, unless otherwise stated in a credit line to the data. 


\section{Background}

Substance use is common among justice-involved youth. Approximately $70 \%$ of arrested juveniles have had prior drug involvement (Belenko \& Logan, 2003), over half of those entering community supervision currently have a substance use problem (Dennis et al., 2019; Scott, Dennis, Grella, Funk, \& Lurigio, 2019), and over onethird have substance use disorders (Aarons, Brown, Hough, Garland, \& Wood, 2001; Wasserman, McReynolds, Schwalbe, Keating, \& Jones, 2010). Substance use has been closely associated with several negative behaviors and outcomes (e.g., delinquency, recidivism, school truancy and dropout, social and family dysfunction), as well as health conditions (e.g., psychopathology, risky sexual behaviors, and sexually transmitted infections) among this vulnerable population of adolescents (Hicks, Iacono, \& McGue, 2010). Justice-involved youth tend to initiate substance use earlier than other adolescents, leading to more problematic substance use and continued involvement with justice authorities (Henggeler, Clingempeel, Brondino, \& Pickrel, 2002; Hoeve, McReynolds, \& Wasserman, 2013; Hoeve, McReynolds, Wasserman, \& McMillan, 2013; Kandel \& Yamaguchi, 2002).

If substance use, especially problematic use, is undetected and untreated among justice-involved youths, they are particularly likely to recidivate (Hoeve, McReynolds, Wasserman, \& McMillan, 2013; Schubert, Mulvey, \& Glasheen, 2011; White, 2019) and to continue offending into adulthood (Hoeve, McReynolds, \& Wasserman, 2013). Thus, substance use prevention, both primary and secondary prevention efforts, for justice-involved youth is critically important to disrupt pathways to multiple potential adverse physical, mental and behavioral health outcomes, as well as to reduce the risk of recidivism. Substance use prevention programs aim to delay or prevent onset of use among those who have never used illegal substances (i.e., primary prevention), as well as to reduce escalation in use among those who have already begun using or relapse after abstinence (i.e., secondary prevention). Fortunately, many evidence-based substance use prevention programs exist. A review of evidencebased interventions for preventing substance use and abuse among youth highlights numerous exemplary prevention programs that can be implemented at the individual, group, family, school or community level (Griffin \& Botvin, 2010; Knight et al., 2019; Shelton, 2005; Tanner-Smith, Durlak, \& Marx, 2018).

Although prevention and treatment programs have been developed, tested and reviewed (e.g., https:// www.crimesolutions.gov/), they remain inconsistently utilized for meeting the needs of justice-involved youth. National data on access to behavioral health services for justice-involved youth are lacking, yet prior studies have found that only $21-25 \%$ of youth referred for treatment services actually received services (Burney Nissen, Butts, Merrigan, \& Kraft, 2006; Dennis et al., 2019). Moreover, having a diagnosis of a disorder is not predictive of receiving services (Sales et al., 2018). Although the juvenile justice system is well poised to deliver evidence-based treatments and prevention programming, such programs tend to be underutilized in justice settings (Leukefeld et al., 2017; Scott et al., 2019; US Census Bureau, 2010). For example, in a study of community supervision agencies in seven states, only $22 \%$ of agencies offered an evidence-based prevention program (Bartkowski, Xu, Avery, Ferguson, \& Johnson, 2018).

Behavioral health services, particularly substance use treatment, are typically provided outside of the juvenile justice system through cross-systems partnerships with local behavioral health providers (Saunders et al., 2016). In a previous paper, only about one in ten CS agencies reported directly providing substance use and/or mental health treatment, while about $90 \%$ of $\mathrm{BH}$ providers directly provide these services (Scott et al., 2019). However, over a third of these agencies/providers were low on collaboration between these two systems. Positive change on this front is also thwarted by organizational and system dynamics, including external behavioral health providers' reliance on diagnoses and treatment that are reimbursable by health insurance (Burney Nissen et al., 2006; Sales et al., 2018). Resources to support substance use prevention may be more difficult for behavioral health providers to acquire given that health insurance does not reimburse such services. At the same time, it is plausible that behavioral health organizations would be more likely to offer substance use prevention than juvenile justice agencies as the former have expertise and experience in direct service provision.

The absence of available information about the availability of prevention programming for justice-involved youth, in either the behavioral health system or the justice system, limits our ability to develop approaches to increase access to and uptake of these programs. Thus, as a critical first step, this paper sought to (1) describe the national availability of substance use prevention within juvenile justice community supervision agencies and their primary behavioral health providers, and (2) examine the relationships between the availability of substance use prevention and agency-level measures of organizational structure, staffing, and youth characteristics.

\section{Methods}

\section{National Survey Description}

This study uses empirical data collected from two organizational sources across the United States: (1) community supervision (CS) agencies in the juvenile justice system (JJS), and (2) their primary behavioral health $(\mathrm{BH})$ providers of substance use and mental health 
treatment. These agencies play a vital role in processing adolescent offenders while aiming to address the complex constellation of needs often presented by this population. A survey instrument was generated to gauge various facets of CS protocol and practice evident in the JJS and the BH sector. The JJS CS surveys and the $\mathrm{BH}$ surveys included questions on data availability; agency characteristics; youth characteristics; behavioral health (substance use, HIV, and mental health) screening, clinical assessment and referral; substance use and HIV/ STI-risk prevention; substance use and mental health treatment; and interagency collaborative activities, family engagement, and technical assistance needs. The questions also focused on whether services were provided directly or through referrals; the names and utilization of evidence-based tools, protocols, and other practices; staff educational levels; and training or experience needs.

\section{Sampling methodology}

Respondent selection was based on a three-stage national probability sampling process that included states, counties, and CS agencies within counties. States and counties were stratified by the number of youth aged 10 to 19 residing in them, as documented in the 2010 Current Population Survey (Gottfredson et al., 2018). In the first stage, the five largest states were selected with certainty. The remaining 15 were selected with probabilities proportionate to the number of youth in five population strata to ensure that less populated states were included in the study.

Within each state, the largest county and any other mega-counties (those with 250,000 or more youth, or half or more of the state's youth in smaller states) were selected with certainty. The remaining counties were selected with probabilities proportionate to the number of youth in those counties. In the two small sampled states organized by judicial district instead of counties, we included all counties/districts.

In the third stage, all CS agencies that served youth on CS in the 192 sampled counties were identified and surveyed $(n=203)$, regardless of the number of youth they served. In states where CS agencies were managed at the state level, key stakeholders at the state level were contacted to help identify the CS agencies and appropriate contact within the sampled counties and to encourage participation in the survey. In states with decentralized systems, all CS agencies within the sampled counties were contacted directly.

Within each sampled county, the selected CS agencies were asked to identify the primary behavioral health providers of substance use and mental health treatment (i.e., those that served the most youth under CS from their sampled county). In over two-thirds of the selected agencies, substance use treatment and mental health treatment were provided by the same agency, but the rest were provided by two different agencies. Most $\mathrm{BH}$ providers were external to the CS agency, but for a small number of CS agencies $(n=12)$, the $\mathrm{BH}$ provider was housed in an internal unit within their own agency. A total of $283 \mathrm{BH}$ providers were identified in the 192 sampled counties.

\section{National survey administration, completion, and weighting}

The agencies/providers were instructed to have staff that were familiar with the agency's organization, priorities, youth under community supervision and the services they receive to fill out the survey. Instructions also stated that it was likely that several staff may need to provide input. Along with the survey instructions, each agency/ provider had a survey coach to help increase the likelihood of accurate and complete responding. Regardless of how many helped put together the answer, each community supervision agency/primary healthcare provider was asked to submit one combined response and have the senior person from the agency sign the informed consent to participate in the national survey. All of the research design, implementation and analysis was conducted under the supervision of Chestnut Health System's Internal Review Board for the protection for human subjects.

Surveys were completed by 195 of the 203 identified CS agencies, for a 96\% CS organizational response rate. Data were weighted based on the inverse of the inclusion probability at each of the three stages (1.0 for certainty state or counties and stage 3 ) and then adjusted for nonresponse within state. The number of agencies overall and those providing a specific service were estimated by multiplying the weighted average number of agencies per county times the actual number of counties $(n=$ 3143) in the United States (excluding the District of Columbia and territories). This calculation generated a national estimate of 3202 CS agencies serving youth under CS.

Of the $283 \mathrm{BH}$ providers identified, 271 surveys (96\%) were completed and returned, again yielding a $96 \%$ response rate. The total number of $\mathrm{BH}$ service providers overall was estimated based on the weighted average number of $\mathrm{BH}$ service providers per county times the number of counties ( $n=3143$ counties). The number of $\mathrm{BH}$ providers providing each specific service were estimated by multiplying the weighted average number of providers providing the service times the number of $\mathrm{BH}$ service providers $(n=4252)$. The data for this analysis combines the records from both the CS survey and the $\mathrm{BH}$ survey. This strategy yielded a weighted total of sample of 7454 agencies/providers (unweighted total is 480). 


\section{Measures}

In this study, the primary outcome variable of interest is whether the respondent from the $\mathrm{CS}$ agency or $\mathrm{BH}$ provider reported directly providing substance use prevention (SUP) services to clients under community supervision. The survey included a list of 57 evidencebased prevention programs; the list also included nonevidence based programs such as DARE. Respondents were asked to endorse any of these or if they used a locally developed program or some other program that was not on the list. Directly providing SUP was defined as the respondent endorsing one or more prevention programs from this list. For more on the survey and SUP items, see Scott et al. (2019). The evidence-based program list was based on the peer-reviewed programs enumerated in the federal Crime Solutions website (CrimeSolutions.gov, n.d) that were rated as having a promising base or strong base of evidence.

To control for county size, we dichotomized counties into "rural" (Beale codes 4, 5, 6, 7, 8, 9) coded as "1" or Urban area counties (Beale codes 1, 2, 3) coded as "0". We retrieved these codes from https://www.ers.usda.gov/data-products/rural-urban-continuum-codes/.

Other agency-level variables, including agency type, staffing, and caseload characteristics, were included as independent variables. Of primary interest was agency type, with CS agencies coded as " 1 " and $\mathrm{BH}$ providers coded as "0." For staffing, we used the number of fulltime equivalent (FTE) doctoral level employees and the number of master level FTEs.

Caseload characteristics included agency/provider-level measures of demographics and substance use characteristics of youth on CS served by the agency in the past year. Respondents were asked to report the percentage of youth on CS served during the past year who were female and the percentage who were racial and ethnic minorities. Respondents could also report if the data for each item was either not accessible or not collected by the agency/provider. About 23\% of the agencies/providers surveyed had missing data on female clients, $23 \%$ had missing data on minorities, and $21 \%$ were missing data on age. Given the high rates of unknown or missing responses on the percentage of female youth caseload, we coded each answer into one of 3 groups: (1) unknown/missing, (2) below the median (less than 30\%), or (3) at or above the median (30\% or more). For percentage of caseload that was from a minority group, we summed the percentages reported across African American, Native American, Asian, Hispanic, multi-racial, or other races and maxed at $100 \%$. The minority caseload median spit was $<8 \%$ and $>=8 \%$. The percentages of youth in the age ranges 14-15, 16-17 and age 18+ were summed and so the age 14+ caseload median was based on $<86 \%$ and $>=86 \%$.
Respondents were asked to report the percentages of the youth caseload with alcohol problems, marijuana problems, and prescription drug problems. Since these three variables are correlated, we constructed a summary variable across these three substances by using the maximum value across these three variables to divide agencies/providers into one of three groups. If all percentages were unknown, we coded the agency/provider into the substance use unknown group. If the respondent reported percentages for the three substances that were never above the median, the agency/provider was coded as being below the median, and if one or more values were above the median, we coded the agency/provider as being above the median.

\section{Analysis}

All analyses were run using IBM SPSS version 25.01. Since our outcome variable was dichotomous, we used the complex samples logistics regression (CSLOGISTIC) procedure. This procedure performs the analysis on the sample using complex sampling methods and weights (described above). The procedure estimates the variances based on the sampling design and reduces the number of agencies/providers back to the original sample size, thus avoiding "artificially" decreasing the standard errors and inflating the power of these analyses. In the first set of analyses, we ran logistic regression analyses for each of the independent variables, where it was the only predictor in the model. The variables with a $p$-value $<.10$ (two-tailed tests) were included simultaneously in the second analysis, which was a final multivariate logistic model.

\section{Results}

For the combined sample, 33\% of agencies/providers provided SUP programming to justice-involved youth. Agency/ provider characteristics are presented in Table 1 . BH providers were significantly more likely to provide SUP than CS agencies (45\% vs. $\left.17 \% ; \chi^{2}(1)=41.0, p<.001\right)$.

A series of univariate logistic regression models of provision of SUP were performed (see Table 2, Column 1 ). In addition to the difference between $\mathrm{BH}$ providers and JJ agencies, two other agency characteristics were significantly associated with the likelihood of providing SUP programming. There was a positive association between the number of master's level FTEs working in the agency/provider and the odds of offering SUP. While there were not significant differences by the demographic composition of the agency's caseload, there were significant differences in the likelihood of providing SUP by the substance use characteristics of the agency's caseload. Compared to agencies where the maximum substance use distribution was above the median, agencies/ providers below the median were significantly less likely 
Table 1 Agency characteristics

\begin{tabular}{|c|c|}
\hline & $\%$ or Mean (SD) \\
\hline \multicolumn{2}{|l|}{ Agency type } \\
\hline Juvenile justice & $43.1 \%$ \\
\hline Behavioral health & $56.9 \%$ \\
\hline \multicolumn{2}{|l|}{ Agency location } \\
\hline Urban county & $36.7 \%$ \\
\hline Rural county & $63.3 \%$ \\
\hline Number of doctoral-level full-time equivalent staff & $0.3(0.7)$ \\
\hline Number of master's-level full-time equivalent staff & $4.1(13.2)$ \\
\hline \multicolumn{2}{|l|}{ Distribution of female youth in the agency's caseload } \\
\hline Females as $<30 \%$ of youth in the caseload & $37.5 \%$ \\
\hline Females as $>=30 \%$ of youth in the caseload & $40.0 \%$ \\
\hline Female distribution unknown & $22.5 \%$ \\
\hline \multicolumn{2}{|l|}{ Distribution of minority youth in the agency's caseload } \\
\hline Minorities as $<8 \%$ of youth in the caseload & $38.6 \%$ \\
\hline Minorities as $>=8 \%$ of youth in the caseload & $38.0 \%$ \\
\hline Minority distribution unknown & $23.4 \%$ \\
\hline \multicolumn{2}{|l|}{ Distribution by age in the agency's caseload } \\
\hline Youth aged 14 and older as < $86 \%$ of youth & $41.4 \%$ \\
\hline Youth aged 14 and older as $>86 \%$ of youth & $37.4 \%$ \\
\hline Age distribution unknown & $21.2 \%$ \\
\hline \multicolumn{2}{|c|}{$\begin{array}{l}\text { Maximum rate of use of alcohol, marijuana, or non-medical prescription } \\
\text { drugs }\end{array}$} \\
\hline Maximum use below the median & $13.0 \%$ \\
\hline Maximum use above the median & $47.9 \%$ \\
\hline Rate of use unknown & $39.1 \%$ \\
\hline
\end{tabular}

Note: Data are weighted to reflect the estimated national population estimate of the 3202 CS agencies plus 4252 BH service providers and in the U.S. and have been adjusted for survey non-response at the state level

to provide SUP to youth. In addition, agencies/providers that were unable to report on the substance use distribution were significantly less likely than agencies/providers reporting maximum substance use above the median to provide SUP.

We entered variables with $p<.10$ from the univariate analyses into a multivariate logistic regression model. (Table 2, Column 2). Controlling for master's level staff and the substance use distribution of the caseload, CS agencies were about $67 \%$ less likely to offer SUP when compared to $\mathrm{BH}$ providers. However, the number of master's level FTEs was no longer significantly associated with the odds of providing SUP once agency type and the substance use distribution were controlled. The differences for the measures of the substance use distribution remained significant in the multivariate model. Agencies/providers below the median on substance use distribution were about $78 \%$ less likely than agencies/ providers above the median to provide SUP. Furthermore, agencies that were unable to provide data on the substance use measures were $67 \%$ less likely to provide SUP than agencies above the median.

\section{Discussion}

Providing SUP in adolescence is critical to avoid worsening substance use trajectories into later adolescent and adulthood. This is particularly true of justice-involved populations for whom outcomes associated with substance use include deeper and sometimes intractable justice involvement. Yet despite the development of evidence-based SU prevention programming, we found that only a third of community supervision and behavioral health agencies provided these programs, evidence-based or otherwise. This finding is consistent with the finding of the lack of evidence-based practices in an earlier juvenile justice survey (Young, Dembo, \& Henderson, 2007).

As would be expected, provision of SUP programming was driven by agency or provider reported of substance use among youth: the greater the reported use and thus service need of youth on an agency or provider's caseload, the greater likelihood of providing preventions programming. These findings are consistent with those of Sales et al. (2018) who found that CS staff largely perceived SUP as a key part of their agency's mission and that greater perceived importance of SUP was associated with greater likelihood of offering programs with these agencies. Nonetheless, data from this national sample found low levels of uptake of SUP among agencies serving justice-involved youth under CS.

The results also indicated that agencies/providers who could not provide youth substance use characteristics were two-thirds less likely to provide SUP. This suggests that perhaps agencies/providers should focus efforts on access and use of data to inform their needs and practices. This paper provided findings that deserve additional comment or were unexpected. First, at a descriptive level, what can be made of the fact that about one third of CS agencies and $\mathrm{BH}$ providers report offering substance use services to justice-involved youth? Without longitudinal data on trends in prevention availability, it is difficult to tell if this estimate should be celebrated as a glass that is one-third full or lamented given that two out of every three agencies do not provide such services. Going forward, trend data would be useful to detect gains or losses on this crucial data point.

Second, it was rather surprising to find no discernible rural-urban differences in SUP aimed at justice-involved youth. Given a wealth of previous studies that reveal pronounced health disparities, justice infrastructure gaps, and a lack of evidence-based programs in rural areas (Bartkowski et al., 2018; Saunders et al., 2016), we presumed that such differences would surface, but they were not observed. It would seem that, at least where this dimension of youth service provision is concerned, 
Table $\mathbf{2}$ Logistic regression models of provision of SUP by agency characteristics

\begin{tabular}{|c|c|c|c|c|}
\hline & $\begin{array}{l}\text { Univariate Models } \\
\text { OR }(95 \% \mathrm{Cl})\end{array}$ & $p$ & $\begin{array}{l}\text { Multivariate Models } \\
\text { OR }(95 \% \mathrm{Cl})\end{array}$ & $p$ \\
\hline \multicolumn{5}{|l|}{ Agency type } \\
\hline Juvenile justice & $0.25(0.10,0.67)$ & .006 & $0.33(0.11,0.94)$ & .037 \\
\hline Behavioral health & Reference & & Reference & \\
\hline \multicolumn{5}{|l|}{ Agency location } \\
\hline Urban county & Reference & & & \\
\hline Rural county & $1.14(0.49,2.64)$ & .759 & & \\
\hline Number of doctoral-level full-time equivalent staff & $1.35(0.85,2.15)$ & .201 & & \\
\hline Number of master's-level full-time equivalent staff & $1.06(1.01,1.11)$ & .027 & $1.05(1.00,1.10)$ & .066 \\
\hline \multicolumn{5}{|l|}{ Distribution of female youth in the agency's caseload } \\
\hline Females as $<30 \%$ of youth in the caseload & $1.00(0.33,3.03)$ & .995 & & \\
\hline Females as $>=30 \%$ of youth in the caseload & Reference & & & \\
\hline Female distribution unknown & $0.68(0.22,2.12)$ & .503 & & \\
\hline \multicolumn{5}{|l|}{ Distribution of minority youth in the agency's caseload } \\
\hline Minorities as $<8 \%$ of youth in the caseload & $0.95(0.31,2.94)$ & .935 & & \\
\hline Minorities as $>=8 \%$ of youth in the caseload & Reference & & & \\
\hline Minority distribution unknown & $0.71(0.27,1.85)$ & .447 & & \\
\hline \multicolumn{5}{|l|}{ Distribution by age in the agency's caseload } \\
\hline Youth aged 14 and older as $<86 \%$ of youth & $1.51(0.54,4.25)$ & .430 & & \\
\hline Youth aged 14 and older as $>86 \%$ of youth & Reference & & & \\
\hline Age distribution unknown & $0.97(0.33,2.82)$ & .948 & & \\
\hline \multicolumn{5}{|c|}{ Maximum rate of use of alcohol, marijuana, or non-medical prescription drugs } \\
\hline Maximum use below the median & $0.18(0.04,0.67)$ & .011 & $0.22(0.07,0.67)$ & .008 \\
\hline Maximum use above the median & Reference & & Reference & \\
\hline Rate of use unknown & $0.39(0.16,0.97)$ & .042 & $0.33(0.12,0.88)$ & .027 \\
\hline
\end{tabular}

rural communities are on par with their urban counterparts. However, our measure of SUP was generated based on a list of evidence-based programs or programs that were locally developed to address needs. Additional research should be conducted to determine if there are rural-urban differences in opting for established programs that have a solid base of evidence (e.g., tested with a control group), programs that are categorized as a promising practice (i.e., some evidence typically without a control group), and those that represent a "grow your own" locally developed program that may have been more minimally evaluated. Our measure does not enable us to draw such fine-grained distinctions, but they could be important. It is possible that measures that are more refined would permit the detection of rural-urban differences. One important potential implication of this study concerns a strategic approach to youth SUP. As noted above, justice-involved youth exhibit a much higher likelihood of substance use than their peers who are not involved in the justice system. The findings reported here do suggest that evidence-based prevention services should likely be expanded beyond the roughly one in three CS agencies or $\mathrm{BH}$ providers that offer such services to justice-involved youth. Given the propensity for youth to recidivate at some point after their initial infraction, it seems worthwhile to make SUP services part of CS programs even when justice-involved youth do not present with a substance use disorder or a pronounced treatment need. At the very least, the effects of programmatic expansion efforts in circumscribed geographical areas could be tested against the treatment as usual modality that is driven by a disorder-based need. The relatively inexpensive cost of prevention when compared with the considerable cost of treatment could recommend the expansion of prevention services if they prove to be useful in comparisons against current approaches. An effort to expand SUP services to many or even all justice-involved youth would align well with related efforts to scale up evidence-based programs to deliver more efficacious results in a manner that proves, in 
the long run, to be much more cost effective (Gottfredson et al., 2018). Here again, however, scaling up efforts should be conducted with attention to local community dynamics (e.g., rural-urban locales, BH providers internal or external to CS agencies).

Several study limitations should be noted. First, the models were estimated using cross-sectional data, so causality cannot be established. A follow-up survey with these agencies is currently being fielded, so future analyses will be able to examine longitudinal data. As noted previously, trends are vital to understanding the trajectory of substance use service offerings provided to justice-involved youth. Second, all data were selfreported, which can lead to bias in over-reporting or under-reporting of agency characteristics. Third, the survey content for the juvenile justice and $\mathrm{BH}$ agencies were tailored to address key variables of these distinct systems, resulting in a limited number of agency characteristics that were measured for both types of agencies. It is likely that there are additional relevant unmeasured agency characteristics that may be correlated with the provision of SUP, such as funding for SUP through contracts or in educational systems. There also were substantial missing data for the caseload characteristics, where respondents were unable to provide the requested information. We considered imputation strategies, but ultimately concluded that the presence and prevalence of missing data are actually important in their own right, as they may identify agencies with less well-developed data systems, which may be a barrier to offering innovative services to meet the needs of youth.

\section{Conclusions}

This study represents an important initial step toward providing a national snapshot of SUP services offered to justice-involved youth. In future efforts, we will continue to track this important facet of service provision to adolescent offenders to determine any marked increases, decreases, or plateaus in such offerings. Until such research can be conducted, we have established an important baseline against which trends can be assessed and upon which strategic decisions can be made to address a need that is alarmingly prevalent among justice-involved youth. A second wave of national surveys have been completed and we hope to use this data, not only to see if we can replicate this paper's findings, but to also look at any changes in the providing of SUP by CS and BH agencies serving youth on community supervision.

\section{Abbreviations}

BH: Behavioral health; Cl: Confidence interval; CS: Community supervision; CSLOGISTIC: Complex samples logistics regression; FTE: Full-time equivalent; JJ: Juvenile justice; JJS: Juvenile justice system; OR: Odds ratio; SD: Standard deviation; SUP: Substance use prevention

\section{Acknowledgements}

The authors thank Kelli Wright for her assistance in preparing the manuscript; Bruce Spenser for his invaluable assistance developing the sampling and weighting strategies; the Survey Advisory Board (Nancy Arrigona, Patrick Flynn, Craig E. Henderson, Matt Hiller, Hannah K. Knudsen, Mark W. Lipsey, Edward (Ned) Loughran, Shawn Marsh, David Morse, Anne Spaulding, Faye Taxman, Gail Wasserman, Carl Wicklund, and Tisha Wiley) for input on the survey and design; the staff who worked on the project; and most of all, the respondents for completing the surveys.

\section{Authors' contributions}

RRF: provided input on statistical design and measurement, conducted statistical analyses. HKK: conceptualized the manuscript, co-wrote initial manuscripts. LSM, JPB, KSE, EHS, and JMS: provided input into conceptualizing, analysis planning and writing the manuscript. CKS: designed and implemented the study and provided review/feedback on of the manuscript. The author(s) read and approved the final manuscript.

\section{Funding}

This study was funded under the Juvenile Justice Translational Research on Interventions for Adolescents in the Legal System (J-TRIALS) Cooperative Agreement, funded at the National Institute on Drug Abuse (NIDA) by the National Institutes of Health $(\mathrm{NIH})$. The authors gratefully acknowledge the collaborative contributions of NIDA and support from the following grant awards: Chestnut Health Systems (U01DA036221); Columbia University (U01DA036226); Emory University (U01DA036233); Mississippi State University (U01DA036176); Temple University (U01DA036225); Texas Christian University (U01DA036224); and University of Kentucky (U01DA036158). The NIDA Science Officer on this project is Tisha Wiley, PhD. The contents of this publication are solely the responsibility of the authors and do not necessarily represent the official views of the $\mathrm{NIDA}, \mathrm{NIH}$, or the participating universities or JJ systems.

\section{Availability of data and materials}

The datasets used and/or analyzed during the current study are available from the corresponding author on reasonable request.

Ethics approval and consent to participate

The study was conducted under the supervision of Chestnut Health Systems' Institutional Review Board (IRB) for the protection of human subjects (IRB Research Study No. 1090-1213). Participation in the study was voluntary and participants could choose not to answer any question without consequences.

\section{Consent for publication}

Not applicable as no individual respondents identified.

\section{Competing interests}

The authors declare that they have no competing interests.

\section{Author details}

${ }^{1}$ Chestnut Health Systems, 448 Wylie Drive, Normal, IL 61761, USA. ${ }^{2}$ College of Medicine, Department of Behavioral Science and Center on Drug and Alcohol Research, University of Kentucky, 845 Angliana Avenue, Room 204, Lexington, KY 40508, USA. ${ }^{3}$ Vagelos College of Physicians and Surgeons, Department of Psychiatry/New York State Psychiatric Institute, Columbia University, 1051 Riverside Drive, Unit 78, New York, NY 10032, USA. ${ }^{4}$ Department of Sociology, University of Texas at San Antonio, One UTSA Circle, San Antonio, TX 78249-0655, USA. ${ }^{5}$ Department of Psychiatry, Columbia University and New York State Psychiatric Institute, 1051 Riverside Drive, \#15, New York, NY 10032, USA. '5ocial Science Research Center, Mississippi State University, 1 Research Boulevard, Suite 103, Mississippi State, MS 39762, USA. ${ }^{7}$ Rollins School of Public Health, Department of Behavioral Sciences and Health Education, Emory University, 1518 Clifton Road NE, Room 570, Atlanta, GA 30322, USA. ${ }^{8}$ Chestnut Health Systems, 221 West Walton Street, Chicago, IL 60610, USA. 
Received: 18 December 2019 Accepted: 22 April 2020

Published online: 13 May 2020

\section{References}

Aarons, G. A., Brown, S. A., Hough, R. L., Garland, A. F., \& Wood, P. A. (2001). Prevalence of adolescent substance use disorders across five sectors of care. Journal of American Academy of Child and Adolescent Psychiatry, 40, 419-426. https://doi.org/10.1097/00004583-200104000-00010.

Bartkowski, J. P., Xu, X., Avery, J. S., Ferguson, D., \& Johnson, F. J. (2018). Good things in small packages? Evaluating an economy of scale approach to behavioral health promotion in rural America. J-Multidisciplinary Scientific Journal, 1, 42-56. https://doi.org/10.3390/j1010006.

Belenko, S., \& Logan, T. K. (2003). Delivering more effective treatment to adolescents: Improving the juvenile drug court model. Journal of Substance Abuse Treatment, 25, 189-211. https://doi.org/10.1016/S0740-5472(03)00123-5.

Burney Nissen, L., Butts, J. A., Merrigan, D., \& Kraft, M. K. (2006). The RWJF reclaiming futures initiative: Improving substance abuse interventions for justice-involved youths. Juvenile and Family Court Journal, 57, 39-51. https:// doi.org/10.1111/j.1755-6988.2006.tb00130.x.

CrimeSolutions.gov. (n.d.) https://www.crimesolutions.gov. Accessed 12 December 2019.

Dennis, M. L., Smith, C. N., Belenko, S., Knight, D., McReynolds, L., Rowan, G., et al. (2019). Operationalizing a behavioral health services cascade of care model: Lessons learned from a 33-site implementation in juvenile justice community supervision. Federal Probation, 83(2), 52-64.

Gottfredson, D. C., Kearley, B., Thornberry, T. P., Slothower, M., Devlin, D., \& Fader, J. J. (2018). Scaling-up evidence-based programs using a public funding stream: A randomized trial of functional family therapy for court-involved youth. Prevention Science, 19, 939-953. https://doi.org/10.1007/s11121-018-0936-z.

Griffin, K. W., \& Botvin, G. J. (2010). Evidence-based interventions for preventing substance use disorders in adolescents. Child and Adolescent Psychiatric Clinics of North America, 19, 505-526. https://doi.org/10.1016/j.chc.2010.03.005.

Henggeler, S. W., Clingempeel, W. G., Brondino, M. J., \& Pickrel, S. G. (2002). Fouryear follow-up of multisystemic therapy with substance-abusing and substance-dependent juvenile offenders. Journal of American Academy of Child and Adolescent Psychiatry, 41, 868-874. https://doi.org/10.1097/ 00004583-200207000-00021.

Hicks, B. M., lacono, W. G., \& McGue, M. (2010). Consequences of an adolescent onset and persistent course of alcohol dependence in men: Adolescent risk factors and adult outcomes. Alcoholism Clinical and Experimental Research, 34, 819-833. https://doi.org/10.1111/j.1530-0277.2010.01154.x.

Hoeve, M., McReynolds, L. S., \& Wasserman, G. A. (2013). The influence of adolescent psychiatric disorder on young adult recidivism. Criminal Justice and Behavior, 40, 1368-1382. https://doi.org/10.1177/0093854813488106.

Hoeve, M., McReynolds, L. S., Wasserman, G. A., \& McMillan, C. (2013). The influence of mental health disorders on severity of re-offending in juveniles. Criminal Justice and Behavior, 40, 289-301. https://doi.org/10.1177/ 0093854812459639

Kandel, D., \& Yamaguchi, K. (2002). Stages of drug involvement in the U.S. population. In D. Kandel (Ed.), Stages and pathways of drug involvement: Examining the gateway hypothesis (pp. 65-89). New York: Cambridge University Press.

Knight, D. K., Joe, G. W., Morse, D. T., Smith, C., Knudsen, H., Johnson, l., et al. (2019). Organizational context and individual adaptability in promoting perceived importance and use of best practices for substance use. Journal of Behavioral Health Services and Research, 46, 192-216. https://doi.org/10.1007/ s11414-018-9618-7.

Leukefeld, C. G., Cawood, M., Wiley, T., Robertson, A. A., Horan Fisher, J., Arrigona, N., et al. (2017). The benefits of community and juvenile justice involvement in organizational research. Journal of Juvenile Justice, 6, 112-124 PMID:28828202.

Rural-Urban Continuum Codes. (n.d.). https://www.ers.usda.gov/data-products/ rural-urban-continuum-codes/. Accessed 12 December 2019.

Sales, J. M., Wasserman, G., Elkington, K. S., Lehman, W., Gardner, S., McReynolds, L., et al. (2018). Perceived importance of substance use prevention in juvenile justice: A multi-level analysis. Health \& Justice, 6, 12. https://doi.org/10.1186/ s40352-018-0070-9.

Saunders, J., Cahill, M., Morral, A. R., Leuschner, K. J., Midgette, G., Hollywood, J. S., et al. (2016). The justice innovation center: Identifying the needs and challenges of criminal justice agencies in small, rural, tribal, and border areas. Santa Monica: RAND Corporation.
Schubert, C. A., Mulvey, E. P., \& Glasheen, C. (2011). Influence of mental health and substance use problems and criminogenic risk on outcomes in serious juvenile offenders. Journal of American Academy of Child and Adolescent Psychiatry, 50, 925-937. https://doi.org/10.1016/j.jaac.2011.06.006.

Scott, C. K., Dennis, M. L., Grella, C. E., Funk, R. R., \& Lurigio, A. J. (2019). Juvenile justice systems of care: Results of a national survey of community supervision agencies and behavioral health providers on services provision and cross-system interactions. Health \& Justice, 7, 11. https://doi.org/10.1186/ s40352-019-0093-x.

Shelton, D. (2005). Patterns of treatment services and costs for young offenders with mental disorders. Journal of Child and Adolescent Psychiatric Nursing, 18, 103-112. https://doi.org/10.1111/j.1744-6171.2005.00013.x.

Tanner-Smith, E. E., Durlak, J. A., \& Marx, R. A. (2018). Empirically based mean effect size distributions for universal prevention programs targeting schoolaged youth: A review of meta-analyses. Prevention Science, 19, 1091-1101. https://doi.org/10.1007/s11121-018-0942-1.

United States Census Bureau. (2010). 2010 Current Population Survey (CPS) Data File. https://www.census.gov/programs-surveys/cps.html. Accessed 12 Dec 2019.

Wasserman, G., McReynolds, L., Schwalbe, C., Keating, J. M., \& Jones, S. A. (2010) Psychiatric disorder, comorbidity, and suicidal behavior in juvenile justice youth. Criminal Justice and Behavior, 37(12), 1361-1376. https://doi.org/10. $1177 / 0093854810382751$.

White, C. (2019). Treatment services in the juvenile justice system: Examining the use and funding of services by youth on probation. Youth Violence and Juvenile Justice, 17(1), 62-87. https://doi.org/10.1177/1541204017728997.

Young, D. W., Dembo, R., \& Henderson, C. E. (2007). A national survey of substance abuse treatment for juvenile offenders. Journal of Substance Abuse Treatment, 32(3), 255-266. https://doi.org/10.1016/j.jsat.2006.12.018.

\section{Publisher's Note}

Springer Nature remains neutral with regard to jurisdictional claims in published maps and institutional affiliations.

Ready to submit your research? Choose BMC and benefit from:

- fast, convenient online submission

- thorough peer review by experienced researchers in your field

- rapid publication on acceptance

- support for research data, including large and complex data types

- gold Open Access which fosters wider collaboration and increased citations

- maximum visibility for your research: over $100 \mathrm{M}$ website views per year

At $\mathrm{BMC}$, research is always in progress.

Learn more biomedcentral.com/submissions 